\title{
Measurement equivalence of child feeding and eating measures across gender, ethnicity, and household food security
}

\author{
Marisol Perez ${ }^{1 *}$, Tara K. Ohrt ${ }^{1}$, Amanda B. Bruening ${ }^{1}$, Aaron B. Taylor ${ }^{4}$, Jeffrey Liew ${ }^{2}$, \\ Ashley M. W. Kroon Van Diest ${ }^{3}$ and Tatianna Ungredda ${ }^{4}$
}

\begin{abstract}
Background: Although there have been extensive studies that make group comparisons on child eating and feeding practices, few studies have examined measurement equivalence to ensure that measures used to make such group comparisons are equivalent across important group characteristics related to childhood obesity.

Methods: Using a sample of 243 caregivers with children between the ages of 4 to 6 years, we conducted a measurement equivalence analysis across gender, ethnicity (Latino versus non-Latino White), and household food security. The subscales of the Child Feeding Questionnaire (CFQ) and the Child Eating Behaviour Questionnaire (CEBQ) were examined separately using a one factor multi-group confirmatory factor analysis.

Results: For the CFQ, Concern about Child Weight and Parental Responsibility subscales were consistent across all groups examined. In contrast, Pressure to Eat, Restriction, and Perceived Parent Weight subscales varied or fit poorly across the groups. For the CEBQ, Emotional Overeating, Enjoyment of Food, and Satiety Responsiveness performed consistently across the groups. On the other hand, Food Fussiness, Desire to Drink, Slowness in Eating, and Emotional Undereating subscales varied or fit poorly across the groups.

Conclusions: Findings from this study suggest both of these measures need continued psychometric work, and group comparisons using some subscales should be interpreted cautiously. Some subscales such as Food Responsiveness and Parental Restriction may be assessing behaviors that occur in food secure households and are less applicable to food insecure environments.
\end{abstract}

Keywords: Child feeding questionnaire, Child eating behaviour questionnaire, Child feeding, Eating behaviors, Latino, Hispanic, Food security, Gender, Measurement invariance

\section{Background}

Research has demonstrated that contextual factors such as gender, food security (e.g., limited or uncertain availability of nutritionally appropriate foods), and ethnicity play a role in the development of pediatric obesity [1-3]. For example, research has found that when compared to boys, girls have more fat mass with a different fat distribution pattern, are less sensitive to insulin across childhood, and are more susceptible to family and environmental risk factors that contribute to pediatric

\footnotetext{
* Correspondence: Marisol.Perez@asu.edu

'Department of Psychology, Arizona State University, 950 S McAllister

Avenue, Tempe, AZ 85287-1104, USA

Full list of author information is available at the end of the article
}

obesity [4]. Boys, in turn, are more physically active throughout childhood and adolescence, receive more benefits from physical activity, and tend to have lower leptin levels when compared to girls [4]. This suggests there may be differential risk factors and susceptibility across groups such as sex. Research on ethnicity has demonstrated that Latino children and adolescents have higher rates of overweight and pediatric obesity than their non-Latino White counterparts [3]. Similarly, there is an association with food insecurity and higher rates of overweight and obesity in children [2, 5-7]. Despite studies demonstrating the influence of these contextual factors on pediatric obesity, limited research has been conducted to ensure that questionnaires on key risk

(c) The Author(s). 2018 Open Access This article is distributed under the terms of the Creative Commons Attribution 4.0 International License (http://creativecommons.org/licenses/by/4.0/), which permits unrestricted use, distribution, and reproduction in any medium, provided you give appropriate credit to the original author(s) and the source, provide a link to the Creative Commons license, and indicate if changes were made. The Creative Commons Public Domain Dedication waiver (http://creativecommons.org/publicdomain/zero/1.0/) applies to the data made available in this article, unless otherwise stated. 
factors for pediatric obesity are invariant across gender, ethnicity, and food security. Measurement invariance is important, because construct validity is threatened when items of a scale function inconsistently across groups.

Existing cross-sectional and longitudinal research suggests that parental beliefs and feeding practices contribute to pediatric obesity [8-12]. Two commonly used measures to assess parental beliefs and feeding practices are the Child Feeding Questionnaire [9] and Child Eating Behaviour Questionnaire [13]. Both questionnaires have been used to make group comparisons despite limited psychometric research examining the appropriateness of these measures across key contextual factors related to pediatric obesity.

The Child Feeding Questionnaire (CFQ), one of the most widely used scales in the child feeding literatures, assesses parent's concern about a child's weight, responsibility for feeding a child, and the extent a parent pressures a child to eat or restricts a child's food intake [9]. The CFQ was initially developed with a 7-factor model and validated among an ethnically diverse sample of mothers and fathers with children ranging from 2- to 11-years of age [9]. However, a replication study of lowincome Latino and African American families with boys and girls failed to replicate the original factor structure and proposed an alternate model [14]. This same study also found cross-cultural conceptual problems resulting in the authors dropping the perceived weight subscales, as well as a number of items in each of the remaining subscales in order to achieve cross-cultural equivalence [14]. Despite these issues, the CFQ has been used to make group comparisons across a number of different groups, such as parents with boys versus girls [15], Latino versus European Americans [11, 16], food secure and food insecure households [5, 17] and among lowincome families without an assessment of food security $[18,19]$.

The Children's Eating Behavior Questionnaire (CEBQ) is a parent-report questionnaire that assesses individual eating styles of children that have been found to relate to pediatric obesity $[12,13]$. The CEBQ was initially developed with an 8 factor model and validated among mothers and fathers with children between the ages of 3- to 8-years old in the United Kingdom [13]. Additional studies have validated the original factor structure among children, with only a slight variation where food responsiveness and emotional overeating at times load onto the same factor $[20,21]$. Within the United States, one study replicated the original factor structure among low income families with pre-school aged children and found measurement equivalence across White and Black participants [22]. Yet, another study of low-income Hispanic and African American families failed to replicate the original factor structure [23]. An additional study of minority low-income families has suggested there may be conceptual issues with some of the scales in the CEBQ [24]. Despite these concerns, the CEBQ has been used to make group comparisons across gender $[21,25]$, and ethnicity [22, 23, 25]. In addition, the CEBQ has been used across socioeconomic status $[25,26]$. If there are problems with measurement invariance, validity of the inferences and interpretations of the results associated with the measure may be threatened.

Research has suggested there may be cross-cultural conceptual problems with the CFQ and CEBQ, and highlighted the need to examine measurement equivalence of these widely used scales, particularly among low-income minority groups [24]. The goal of the current study was to examine measurement equivalence of the CFQ and CEBQ across key contextual factors that influence pediatric obesity (gender, ethnicity, food security). To facilitate across study comparisons of both measures, the current study targeted caregivers with children between the ages of 4- to 6-years old. Both measures have psychometric studies that recruited families from preschool centers, thereby increasing our ability to compare our findings to the extant literature [14, 22-24, 27].

\section{Method}

\section{Participants and procedures}

This study includes 243 caregivers (169 maternal caregivers) with children between the ages of 4- to 6-years old who resided in the home with the children the majority of the time. Table 1 displays the sample characteristics. Approximately $51 \%$ of the children were male, and $33.6 \%$ were Latino. The majority of caregivers (51.5\%) reported a monthly household income of $\$ 3000$ or below. There were 72 children whose caregiver reported household food insecurity. The number of persons per household ranged from 2 to $10(M=4.27, S D=1.14)$. Child body mass index (BMI) was calculated as BMIfor-age (age- and sex-specific) using experimentermeasured child weight and height with Centers for Disease Control and Prevention (CDC) growth charts [28]. Among the children, $66.7 \%$ had a BMI percentile score below the 85th percentile and considered of healthy weight, while $23.8 \%$ of the sample had a BMI percentile score between 85th and 95th and considered overweight, and $9.5 \%$ of the children were considered obese with a 95th or greater BMI percentile score.

Using flyers, participants were recruited from waiting rooms of pediatricians' offices, daycare centers, preschools, and local stores or businesses that were frequented by families. Families called if they were interested in participating in the study and were screened by phone. Caregivers were excluded if (1) they were unable to use English fluently, (2) had a significant 
Table 1 Means, standard deviation, and sample characteristics

\begin{tabular}{|c|c|c|c|c|c|c|c|}
\hline Characteristic/Scale & Total $(N=243)$ & Males $(n=125)$ & Females $(n=116)$ & Latino $(n=81)$ & Non-Latino $(n=160)$ & Insecure $(n=72)$ & $\begin{array}{l}\text { Secure } \\
(n=167)\end{array}$ \\
\hline$\overline{\text { Age }}$ & $4.80(0.85)$ & & & & & & \\
\hline \multicolumn{8}{|l|}{ Income } \\
\hline $0-\$ 2000$ & $36.4 \%$ & & & & & & \\
\hline$\$ 2001-\$ 3000$ & $15.1 \%$ & & & & & & \\
\hline$\$ 3001-\$ 5000$ & $15.5 \%$ & & & & & & \\
\hline$\$ 5001-\$ 7000$ & $9.2 \%$ & & & & & & \\
\hline$\$ 7001$ - more & $23.8 \%$ & & & & & & \\
\hline \multicolumn{8}{|l|}{ Child BMI } \\
\hline Healthy & $66.7 \%$ & & & & & & \\
\hline Overweight & $23.8 \%$ & & & & & & \\
\hline Obese & $9.5 \%$ & & & & & & \\
\hline \multicolumn{8}{|l|}{ Caregiver BMI } \\
\hline Healthy & $36.8 \%$ & & & & & & \\
\hline Overweight & $27.1 \%$ & & & & & & \\
\hline Obese & $36.1 \%$ & & & & & & \\
\hline \multicolumn{8}{|l|}{ Child feeding questionnaire } \\
\hline Perceived Parent Weight & $12.81(1.83)$ & $12.75(1.64)$ & $12.86(2.02)$ & $12.85(1.70)$ & $12.78(1.90)$ & $13.29(1.81)$ & $12.60(1.82)$ \\
\hline Concern Child Weight & $6.67(3.86)$ & $6.53(3.86)$ & 6.83(3.88) & $7.59(4.14)$ & $6.21(3.64)$ & $6.97(3.99)$ & $6.53(3.83)$ \\
\hline Parental Responsibility & $13.26(2.18)$ & $13.12(2.36)$ & $13.41(1.96)$ & $13.51(2.65)$ & 13.14(1.90) & $13.71(1.96)$ & $13.06(2.25)$ \\
\hline Restriction & $27.28(7.82)$ & $27.59(7.91)$ & $26.94(7.73)$ & $27.09(9.05)$ & $27.37(7.14)$ & 28.18(7.99) & $26.85(7.77)$ \\
\hline Pressure to Eat & $10.52(4.44)$ & $10.99(4.47)$ & $10.04(4.38)$ & $10.86(4.14)$ & $10.35(4.59)$ & $11.33(4.72)$ & $10.21(4.30)$ \\
\hline \multicolumn{8}{|c|}{ Child eating behaviour questionnaire } \\
\hline Food Responsiveness & $11.56(4.03)$ & $11.64(4.07)$ & $11.47(4.00)$ & $11.38(4.87)$ & 11.64(3.54) & $12.17(4.96)$ & $11.24(3.44)$ \\
\hline Emotional Overeating & $6.83(2.93)$ & $6.78(2.87)$ & $6.89(2.99)$ & $6.95(3.41)$ & $6.78(2.66)$ & 7.24(3.44) & $6.67(2.68)$ \\
\hline Enjoyment of Food & $14.09(2.98)$ & $14.07(2.99)$ & $14.11(2.97)$ & $14.09(3.05)$ & $14.09(2.95)$ & $14.21(3.28)$ & 14.01(2.83) \\
\hline Desire to Drink & $9.83(3.21)$ & $10.31(3.19)$ & $9.30(3.15)$ & $10.26(3.29)$ & $9.61(3.15)$ & $10.69(3.32)$ & $9.39(3.05)$ \\
\hline Satiety Responsive & $15.29(3.29)$ & 15.19(3.33) & 15.39(3.28) & $14.69(3.59)$ & $15.59(3.10)$ & $14.88(3.52)$ & $15.46(3.14)$ \\
\hline Slowness in Eating & $11.75(3.12)$ & $11.68(2.93)$ & $11.82(3.32)$ & $11.36(3.46)$ & $11.94(2.93)$ & $11.61(3.20)$ & 11.82(3.05) \\
\hline Emotional Undereat & $10.79(3.21)$ & $10.70(3.18)$ & 10.88(3.24) & 10.39(3.13) & $10.99(3.24)$ & $10.50(3.34)$ & 10.88(3.15) \\
\hline Food Fussiness & $14.64(5.34)$ & $18.20(5.30)$ & $17.04(5.33)$ & $16.79(4.86)$ & $18.08(5.53)$ & $17.69(5.33)$ & $17.70(5.33)$ \\
\hline
\end{tabular}

Note: Total = total sample; Insecure = food insecurity; Secure = food security; Income is monthly household income. Child BMI percentile score below the 85th percentile is healthy weight, percentile score between 85th -95th is considered overweight, and 95th percentile score or greater is considered obese. Caregiver BMI was calculated using experimenter-measured weight and height. Data reported as Means (SD)

disability that would prevent them from completing the tasks in this proposal, such as blindness, or (3) did not have a child between the ages of 4- to 6-years old. Parents completed online questionnaires on their behavior patterns and those of their children, and were paid for their participation.

\section{Measures}

\section{Child Feeding Questionnaire (CFQ)}

The CFQ is a 28 item measure given to parents that assesses parent's perceived responsibility for feeding, perceived parent weight across development, concern about child weight and risk for being overweight, food restriction, and pressure to eat $[12,13]$. Items are rated on a scale from 1 to 5 . Scores on the subscales range from 4 to 20 for Perceived Parent Weight, 3 to 15 for Concern about Child Weight, 3 to 15 for Parental Responsibility, 8 to 40 for Restriction, and 4 to 20 for Pressure to Eat. Confirmatory factor analyses have tested the factor structure of this measure across Caucasian and Latino samples [14]. Among Caucasian and Latino samples, internal reliability coefficients range from .70 to .92 [14]. In the current study, internal reliability coefficients are: .64 Parent Perceived Weight, .85 Concern about Child weight, .88 Parental Responsibility, .81 Restriction, and .75 Pressure to Eat. 


\section{Children's Eating Behaviour Questionnaire (CEBQ)}

The Children's Eating Behaviour Questionnaire is a 35 item measure that assesses parents' perceptions on child's eating behaviors with items rated on a scale from 1 to 5 . The subscales include child's responsiveness to food (scores range 5-25), enjoyment of food (scores range 4-20), satiety responsiveness (scores range 5-25), slowness in eating (scores range 4-20), food fussiness (scores range 6-30), emotional overeating (scores range 4-20), emotional undereating (scores range 4-20), and desire for drinks (scores range 3-15) [13]. Past research reports internal reliability coefficients ranging from .74 to .91 [13]. In the current study, internal reliability coefficients are: .79 Food Responsiveness, .86 Emotional Overeating, .82 Enjoyment of Food, .87 Desire to Drink, .71 Satiety Responsiveness, .74 Slowness in Eating, .73 Emotional Undereating, and .88 Food Fussiness.

\section{Food security}

The United States Department of Agriculture Household Food Security questionnaire was used to assess food security $[29,30]$. This is an 18 item questionnaire that categorizes families into high food security (score of 0 ), marginal food (scores of 1-2) security, low food security (scores $3-7$ ) and very low food security (scores of 8 or more). This measure has been used with different ethnic groups [31]. For this study, individuals with scores of 2 or less were considered food secure, and individuals with a score of 3 or more were considered food insecure. However, among those with a score of 1 or 2 , if caregivers reported skipping meals or not eating so that their children may eat, they were classified as food insecure.

\section{Data analytic approach}

Descriptive analyses were conducted using SPSS software. Descriptive statistics were calculated by gender, ethnicity, and household food security via independent sample $t$ tests. Internal consistency was calculated and reported across all of the groups.

\section{Power analyses}

Research has determined that no general rule of thumb will suffice when determining the needed sample size for CFA [32, 33]. Research has found that communality of indicators (i.e., reliability of the indicators), and factor overdetermination (i.e., number of factors/number of indicators) are important when determining sample size requirements for CFAs [33, 34]. MacCallum et al. suggested communalities of .6 or greater, and a minimum of 3 indicators per factor [34]. Using Monte Carlo data simulation techniques, Wolf and colleagues [32] found that for CFAs with one factor loading of .50 and with 3 or 4 indicators required a sample size of 190 or a sample size of 90 if the indicators increased to 6 or 8 . Given the findings from Wolf and colleagues [32], our sample size should be sufficient. To further ensure sufficient power, retrospectively the RMSEA analyses were all entered into the Preacher and Coffman online software and yielded power of .80 through .98 [35].

\section{Measurement invariance}

To conduct the measurement equivalence analyses, confirmatory factor analyses (CFAs) in Mplus [36] were conducted following the procedures recommended by Mulaik and Millsap [37]. For all analyses, we used full information maximum likelihood to handle missing data as this method produces more unbiased results [38]. Little MCAR tests with expectation-maximization methods were performed to evaluate if data was missing at random. For the CFQ, missing data for all the items ranged from 1.2 to $3.2 \%$, and analyses indicate the data is indeed missing at random, $\chi^{2}(247)=225.451, p=.83$. For the CEBQ, missing data for all items ranges from 1.6 to $2.8 \%$ and analyses indicate the data is missing at random, $\mathrm{X}^{2}(101)=116.648, p=.14$. We evaluated model fit using various fit statistics, including the chi-square significance test [39], the root-mean-square error of approximation (RMSEA) [40], and the comparative fit index (CFI) [41]. The Akaike Information Criterion (AIC) was used to compare different models with the lowest AIC value relative to another model is the optimal model [41]. Adequate fit was considered to be a lack of significance on chi-square difference test, a RMSEA $<.08$, and CFI $>.90[41,42]$. To examine measurement invariance across groups (males vs. females, Latino vs. non-Latino Whites, food secure vs. food insecure) we used a step-wise approach (instead of constraining all the parameters) to identify at which point invariance is no longer achieved between the two groups [43]. The first step entails examining single group solutions of each subscale of the CFQ and CEBQ for each subgroup. For example, we examined Pressure to Eat subscale of CFQ among males and females, separately. If model fit was adequate for each of these samples, then we proceeded to the next step; otherwise, we stopped. The second step involved examining configural invariance, which assesses if the number of factors and pattern of indicator-factor loadings fit both groups equally well. Both the factor loadings and item thresholds were allowed to be freely estimated in each group. If model fit was adequate, then we proceeded to the next step; otherwise, we stopped. The third step examined loading invariance, which constrained loadings to be equal across both groups. Differences in factor loadings would suggest that items were not assessing the same construct across groups. For example, this test would examine if the items in the Pressure to Eat subscale of the CFQ were associated with comparable relationships to the latent construct 
(parents pressuring their children to eat) across the gender groups in this sample. If model fit was adequate, then we proceeded to the next step; otherwise, we stopped. The fourth step examined item intercept invariance, which constrained loadings and intercepts to be equal across both groups. Lack of invariance would suggest that the groups had different thresholds for endorsing a particular item, such that one group endorsed the item at higher severity despite having similar levels of the latent construct. For example, Latino parents may produce different raw scores on the items that comprise the Pressure to Eat subscale than non-Latino parents despite having similar global Pressure to Eat subscale scores.

\section{Results}

Means and standard deviations on all subscales across all groups are reported in Table 1.

\section{Invariance across male and female samples \\ CFQ}

Independent CFAs indicated poor fit of the single latent factor for either females or males on Perceived Parent
Weight, Restriction, and Pressure to Eat subscales. Throughout gender invariance examination, males were used as the reference group. Results support configural, loading, and intercept invariance for the Concern about Child Weight and Parental Responsibility subscales. This indicates these subscales appear to be assessing the same underlying constructs across males and females, and the groups are endorsing items at similar thresholds. Comparatively, the AIC values indicate that the intercept invariance model appears to be the optimal model for both subscales (Table 2).

\section{CEBQ}

Independent CFAs indicated poor fit of the single latent factor for either females or males on Emotional Overeating, Slowness in Eating, Emotional Undereating and Food Fussiness. Results support configural, loading, and intercept invariance for the Food Responsiveness, Enjoyment of Food, and Satiety Responsiveness subscales indicating these subscales appear to be assessing the same underlying constructs across males and females. In addition, males and

Table 2 Independent and multi-group CFAs for parent feeding in males and females

\begin{tabular}{|c|c|c|c|c|}
\hline \multirow[b]{2}{*}{ Subscale } & \multicolumn{3}{|l|}{ Overall fit indices } & \multirow{2}{*}{$\begin{array}{l}\text { Comparative fit } \\
\text { AIC }\end{array}$} \\
\hline & $x^{2}(d f)$ & CFI & RMSEA $(90 \% \mathrm{Cl})$ & \\
\hline \multicolumn{5}{|l|}{ Child feeding questionnaire } \\
\hline \multicolumn{5}{|l|}{ Perceived parent weight } \\
\hline Female & $4.063(2), p=.13$ & .960 & $.091(.000-.220)$ & - \\
\hline Male & $37.804(2), p<.01$ & .687 & $.395(.291-.509)$ & - \\
\hline \multicolumn{5}{|l|}{ Concern child weight } \\
\hline Female & $0.000(0)$ & 1.000 & .000 & - \\
\hline Male & $0.000(0)$ & 1.000 & .000 & - \\
\hline Configural Invariance & $0.000(0)$ & 1.000 & .000 & 36.000 \\
\hline Loading Invariance & $1.851(2), p=.40$ & 1.000 & $.000(.000-.125)$ & 33.851 \\
\hline Intercept Invariance & $4.212(5), p=.52$ & 1.000 & $.000(.000-.082)$ & 30.212 \\
\hline \multicolumn{5}{|l|}{ Parental responsibility } \\
\hline Female & $0.000(0)$ & 1.000 & .000 & - \\
\hline Male & $0.000(0)$ & 1.000 & .000 & - \\
\hline Configural Invariance & $0.000(0)$ & 1.000 & .000 & 36.000 \\
\hline Loading Invariance & $1.844(2), p=.40$ & 1.000 & $.000(.000-.075)$ & 34.756 \\
\hline Intercept Invariance & $6.854(5), p=.23$ & .996 & $.039(.000-.104)$ & 32.854 \\
\hline \multicolumn{5}{|l|}{ Restriction } \\
\hline Female & $127.385(20), p<.01$ & .711 & $.208(.174-.243)$ & \\
\hline Male & $200.813(20), p<.01$ & .599 & $.280(.246-.316)$ & \\
\hline \multicolumn{5}{|l|}{ Pressure to eat } \\
\hline Female & $5.092(2), p=.08$ & .975 & $.112(.000-.237)$ & \\
\hline Male & $4.140(2), p=.13$ & .981 & $.096(.000-.230)$ & \\
\hline
\end{tabular}

Note. Italicized analyses represent independent CFAs examining each subscale as a latent single factor. Perceived Parent Weight has 4 indicators, Concern about Child Weight has 3 indicators, Parental Responsibility has 3 indicators, Restriction has 8 indicators and Pressure to Eat has 4 indicators. AIC is a comparative fit index for two or more groups 
females appear to be endorsing items at similar thresholds. The AIC values indicated the intercept invariance model to be the optimal model for all of these subscales. However, Desire to Drink only achieved configural and loading, with the model poorly fitting for intercept invariance. The AIC value further confirms the configural invariance model to be the optimal model for Desire to Drink Table 3.

Table 3 Independent and multi-group CFAs for child eating in males and females

\begin{tabular}{|c|c|c|c|c|}
\hline \multirow[b]{2}{*}{ Subscale } & \multicolumn{3}{|l|}{ Overall fit indices } & \multirow{2}{*}{$\begin{array}{l}\text { Comparative fit } \\
\text { AIC }\end{array}$} \\
\hline & $x^{2}(d f)$ & CFI & RMSEA $(90 \% \mathrm{Cl})$ & \\
\hline \multicolumn{5}{|c|}{ Child eating behaviour questionnaire } \\
\hline \multicolumn{5}{|l|}{ Food responsiveness } \\
\hline Female & $6.485(5), p=.26$ & .991 & $.049(.000-.141)$ & - \\
\hline Male & $6.844(5), p=.23$ & .991 & $.057(.000-.150)$ & - \\
\hline Configural Invariance & $13.329(10), p=.21$ & .991 & $.037(.000-.084)$ & 73.329 \\
\hline Loading Invariance & $14.308(14), p=.43$ & .999 & $.010(.000-.064)$ & 66.308 \\
\hline Intercept Invariance & $14.661(19), p=.74$ & 1.000 & $.000(.000-.041)$ & 56.661 \\
\hline \multicolumn{5}{|l|}{ Emotional overeating } \\
\hline Female & $2.280(2), p=.32$ & .999 & $.034(.000-.185)$ & - \\
\hline Male & $8.973(2), p=.01$ & .977 & $.174(.070-.297)$ & - \\
\hline \multicolumn{5}{|l|}{ Enjoyment of food } \\
\hline Female & $0.462(2), p=.79$ & 1.000 & $.000(.000-.113)$ & - \\
\hline Male & $1.041(2), p=.59$ & 1.000 & $.000(.000-.153)$ & - \\
\hline Configural Invariance & $1.504(4), p=.83$ & 1.000 & $.000(.000-.058)$ & 49.504 \\
\hline Loading Invariance & $3.590(7), p=.83$ & 1.000 & $.000(.000-.048)$ & 45.590 \\
\hline Intercept Invariance & $3.988(11), p=.97$ & 1.000 & $.000(.000-.000)$ & 37.988 \\
\hline \multicolumn{5}{|l|}{ Desire to drink } \\
\hline Female & $0.000(0)$ & 1.000 & .000 & - \\
\hline Male & $0.000(0)$ & 1.000 & .000 & - \\
\hline Configural Invariance & $0.000(0)$ & 1.000 & .000 & 36.000 \\
\hline Loading Invariance & $6.196(2), p=.05$ & .991 & $.094(.012-.182)$ & 38.196 \\
\hline Intercept Invariance & $14.395(5), p=.01$ & .979 & $.089(.037-.144)$ & 40.395 \\
\hline \multicolumn{5}{|l|}{ Satiety responsiveness } \\
\hline Female & $2.429(5), p=.79$ & 1.000 & $.000(.000-.082)$ & - \\
\hline Male & $2.271(5), p=.81$ & 1.000 & $.000(.000-.080)$ & - \\
\hline Configural Invariance & $4.700(10), p=.91$ & 1.000 & $.000(.000-.028)$ & 64.700 \\
\hline Loading Invariance & $9.674(14), p=.79$ & 1.000 & $.000(.000-.042)$ & 61.674 \\
\hline Intercept Invariance & $12.222(19), p=.88$ & 1.000 & $.000(.000-.029)$ & 54.222 \\
\hline \multicolumn{5}{|l|}{ Slowness in eating } \\
\hline Female & $6.864(2), p=.03$ & .932 & $.140(.035-.261)$ & - \\
\hline Male & $18.374(2), p<.01$ & .909 & $.267(.164-.384)$ & - \\
\hline \multicolumn{5}{|l|}{ Emotional undereating } \\
\hline Female & $6.013(2), p=.05$ & .961 & $.127(.005-.250)$ & - \\
\hline Males & $6.481(2), p=.04$ & .967 & $.140(.027-.266)$ & - \\
\hline \multicolumn{5}{|l|}{ Food fussiness } \\
\hline Female & $55.537(9), p<.01$ & .880 & $.204(.155-.257)$ & - \\
\hline Male & $35.779(9), p<.01$ & .932 & $.161(.108-.218)$ & - \\
\hline
\end{tabular}




\section{Invariance across Latino and non-Latino samples CFQ}

Independent CFAs indicated poor fit of the single latent factor for either Latinos or Non-Latinos on Perceived Parent Weight, Restriction, and Pressure to Eat subscales. Results support configural, loading, and intercept invariance for Concern about Child Weight subscale. This subscale appears to be assessing the same underlying construct across ethnic groups, and the groups appear to be endorsing items at similar thresholds. Comparatively, the loading invariance model appears to be the optimal model for this subscale. Parental Responsibility achieved configural invariance but not loading invariance (Table 4).

\section{CEBQ}

Independent CFAs indicated poor fit of the single latent factor for either Latinos or Non-Latinos on Slowness in Eating, Emotional Undereating, and Food Fussiness. Results support configural, loading, and intercept invariance for all other scales. For Food Responsiveness, the best fitting model was the loading invariance model when compared to the other models. For Emotional
Overeating, the configural invariance model was the best fitting of the three invariance models. For Enjoyment of food, Desire to Drink, and Satiety Responsiveness the intercept model was the optimal model with the lowest AIC values (Table 5).

\section{Invariance across food secure and insecure households CFQ}

Independent CFAs indicated poor fit of the single latent factor for either food secure or insecure households on Perceived Parent Weight, Restriction, and Pressure to Eat. Results support configural, loading and intercept invariance for Concern about Child Weight, with the intercept invariance model being the best fitting based on AIC values. For the Parental Responsibility subscale, only configural invariance was achieved, with loading invariance model fitting poorly (Table 6).

\section{CEBQ}

Independent CFAs indicated poor fit of the single latent factor for either food secure or insecure households on Food Responsiveness, Emotional Overeating, Slowness in Eating, Emotional Undereating, and Food Fussiness.

Table 4 Independent and multi-group CFAs for parent feeding in non-Latino and Latino samples

\begin{tabular}{|c|c|c|c|c|}
\hline \multirow[b]{2}{*}{ Subscale } & \multicolumn{3}{|l|}{ Overall fit indices } & \multirow{2}{*}{$\begin{array}{l}\text { Comparative fit } \\
\text { AIC }\end{array}$} \\
\hline & $x^{2}(d f)$ & $\mathrm{CFI}$ & RMSEA ( $90 \% \mathrm{Cl})$ & \\
\hline \multicolumn{5}{|l|}{ Child feeding questionnaire } \\
\hline \multicolumn{5}{|l|}{ Perceived parent weight } \\
\hline Non-Latino & $38.046(2), p<.01$ & .734 & $.337(.248-.434)$ & - \\
\hline Latino & $2.509(2), p=.29$ & .986 & $.056(.000-.237)$ & - \\
\hline \multicolumn{5}{|l|}{ Concern child weight } \\
\hline Non-Latino & $0.000(0)$ & 1.000 & .000 & - \\
\hline Latino & $0.000(0)$ & 1.000 & .000 & - \\
\hline Configural Invariance & $0.000(0)$ & 1.000 & .000 & 36.000 \\
\hline Loading Invariance & $0.152(2), p=.93$ & 1.000 & $.000(.000-.041)$ & 32.152 \\
\hline Intercept Invariance & $9.751(5), p=.08$ & .984 & $.063(.000-.122)$ & 35.751 \\
\hline \multicolumn{5}{|l|}{ Parental responsibility } \\
\hline Non-Latino & $0.000(0)$ & 1.000 & .000 & - \\
\hline Latino & $0.000(0)$ & 1.000 & .000 & - \\
\hline Configural Invariance & $0.000(0)$ & 1.000 & .000 & 36.000 \\
\hline Loading Invariance & $10.143(2), p<.01$ & .981 & $.131(.059-.215)$ & 42.143 \\
\hline \multicolumn{5}{|l|}{ Restriction } \\
\hline Non-Latino & $221.360(20), p<.01$ & .547 & $.252(.222-.282)$ & - \\
\hline Latino & $147.769(20), p<.01$ & .680 & $.283(.241-.326)$ & - \\
\hline \multicolumn{5}{|l|}{ Pressure to eat } \\
\hline Non-Latino & $3.787(2), p=.15$ & .990 & $.075(.000-.190)$ & - \\
\hline Latino & $5.446(2), p=.07$ & .939 & $.147(.000-.301)$ & - \\
\hline
\end{tabular}

Note. Italicized analyses represent independent CFAs examining each subscale as a single factor. Perceived Parent Weight has 4 indicators, Concern about Child Weight has 3 indicators, Parental Responsibility has 3 indicators, Restriction has 8 indicators and Pressure to Eat has 4 indicators. AIC is a comparative fit index for two or more groups 
Table 5 Independent and multi-group CFAs for child eating in Non-Latino and Latinos

\begin{tabular}{|c|c|c|c|c|}
\hline \multirow[b]{2}{*}{ Subscale } & \multicolumn{3}{|l|}{ Overall fit indices } & \multirow{2}{*}{$\begin{array}{l}\text { Comparative fit } \\
\text { AIC }\end{array}$} \\
\hline & $x^{2}(d f)$ & $\mathrm{CFI}$ & RMSEA (90\% Cl) & \\
\hline \multicolumn{5}{|c|}{ Child eating behaviour questionnaire } \\
\hline \multicolumn{5}{|l|}{ Food responsiveness } \\
\hline Non-Latino & $6.408(5), p=.27$ & .992 & $.042(.000-.124)$ & - \\
\hline Latino & $4.478(5), p=.48$ & 1.000 & $.000(.000-.147)$ & - \\
\hline Configural Invariance & $10.892(10), p=.37$ & .998 & $.019(.000-.074)$ & 70.892 \\
\hline Loading Invariance & $12.700(14), p=.55$ & 1.000 & $.000(.000-.057)$ & 64.700 \\
\hline Intercept Invariance & $28.388(19), p=.08$ & .974 & $.045(.000-.078)$ & 70.388 \\
\hline \multicolumn{5}{|l|}{ Emotional overeating } \\
\hline Non-Latino & $2.467(2), p=.29$ & .999 & $.038(.000-.167)$ & - \\
\hline Latino & $0.339(2), p=.84$ & 1.000 & $.000(.000-.124)$ & - \\
\hline Configural Invariance & $2.803(4), p=.59$ & 1.000 & $.000(.000-.083)$ & 50.803 \\
\hline Loading Invariance & $12.486(7), p=.09$ & .990 & $.057(.000-.108)$ & 54.486 \\
\hline Intercept Invariance & $22.522(11), p=.02$ & .980 & $.066(.025-.105)$ & 56.522 \\
\hline \multicolumn{5}{|l|}{ Enjoyment of food } \\
\hline Non-Latino & $1.600(2), p=.45$ & 1.000 & $.000(.000-.147)$ & - \\
\hline Latino & $0.539(2), p=.76$ & 1.000 & $.000(.000-.149)$ & - \\
\hline Configural Invariance & $2.139(4), p=.71$ & 1.000 & $.000(.000-.072)$ & 50.139 \\
\hline Loading Invariance & $4.800(7), p=.68$ & 1.000 & $.000(.000-.062)$ & 46.800 \\
\hline Intercept Invariance & $9.141(11), p=.61$ & 1.000 & $.000(.000-.059)$ & 43.141 \\
\hline \multicolumn{5}{|l|}{ Desire to drink } \\
\hline Non-Latino & $0.000(0)$ & 1.000 & .000 & - \\
\hline Latino & $0.000(0)$ & 1.000 & .000 & - \\
\hline Configural Invariance & $0.000(0)$ & 1.000 & .000 & 36.000 \\
\hline Loading Invariance & $0.344(2), p=.84$ & 1.000 & $.000(.000-.072)$ & 32.344 \\
\hline Intercept Invariance & $3.740(5), p=.59$ & 1.000 & $.000(.000-.077)$ & 29.740 \\
\hline \multicolumn{5}{|l|}{ Satiety responsiveness } \\
\hline Non-Latino & $1.689(5), p=.89$ & 1.000 & $.000(.000-.050)$ & - \\
\hline Latino & $4.471(5), p=.45$ & 1.000 & $.000(.000-.151)$ & - \\
\hline Configural Invariance & $6.420(10), p=.78$ & 1.000 & $.000(.000-.048)$ & 66.420 \\
\hline Loading Invariance & $13.890(14), p=46$ & 1.000 & $.000(.000-.062)$ & 65.890 \\
\hline Intercept Invariance & $22.116(19), p=.28$ & .988 & $.026(.000-.065)$ & 64.116 \\
\hline \multicolumn{5}{|l|}{ Slowness in eating } \\
\hline Non-Latino & $21.501(2), p<.01$ & .861 & $.248(.160-.347)$ & - \\
\hline Latino & $3.795(2), p=.15$ & .980 & $.106(.000-.268)$ & - \\
\hline \multicolumn{5}{|l|}{ Emotional undereating } \\
\hline Non-Latino & $11.464(2), p<.01$ & .951 & $.173(.085-.275)$ & - \\
\hline Latino & $2.221(2), p=.33$ & .995 & $.037(.000-.228)$ & - \\
\hline \multicolumn{5}{|l|}{ Food fussiness } \\
\hline Non-Latino & $57.979(9), p<.01$ & .916 & $.185(.141-.232)$ & - \\
\hline Latino & $22.373(9), p<.01$ & .928 & $.136(.066-.208)$ & - \\
\hline
\end{tabular}

Note. Italicized analyses represent independent CFAs examining each subscale as a single latent factor. Food Responsiveness has 5 indicators, Emotional Overeating has 4 indicators, Enjoyment of Food has 4 indicators, Desire to Drink has 3 indicators, Satiety Responsiveness has 5 indicators, Slowness in Eating has 4 indicators, Emotional Undereating has 4 indicators, and Food Fussiness has 6 indicators. AIC is a comparative fit index for two or more groups 
Table 6 Independent and multi-group CFAs for parent feeding in food secure and insecure households

\begin{tabular}{|c|c|c|c|c|}
\hline \multirow[b]{2}{*}{ Subscale } & \multicolumn{3}{|l|}{ Overall fit indices } & \multirow{2}{*}{$\begin{array}{l}\text { Comparative fit } \\
\text { AIC }\end{array}$} \\
\hline & $x^{2}(d f)$ & $\mathrm{CFI}$ & RMSEA (90\% Cl) & \\
\hline \multicolumn{5}{|l|}{ Child feeding questionnaire } \\
\hline \multicolumn{5}{|l|}{ Perceived parent weight } \\
\hline Food Secure & $36.347(2), p<.01$ & .724 & $.322(.235-.417)$ & - \\
\hline Food Insecure & $2.912(2), p=.23$ & .973 & $.080(.000-.263)$ & - \\
\hline \multicolumn{5}{|l|}{ Concern child weight } \\
\hline Food Secure & $0.000(0)$ & 1.000 & .000 & - \\
\hline Food Insecure & $0.000(0)$ & 1.000 & .000 & - \\
\hline Configural Invariance & $0.000(0)$ & 1.000 & .000 & 36.000 \\
\hline Loading Invariance & $3.195(2), p=.20$ & .996 & $.050(.000-.148)$ & 35.195 \\
\hline Intercept Invariance & $6.362(5), p=.27$ & .996 & $.034(.000-.101)$ & 32.362 \\
\hline \multicolumn{5}{|l|}{ Parental responsibility } \\
\hline Food Secure & $0.000(0)$ & 1.000 & .000 & - \\
\hline Food Insecure & $0.000(0)$ & 1.000 & .000 & - \\
\hline Configural Invariance & $0.000) 0)$ & 1.000 & .000 & 36.000 \\
\hline Loading Invariance & $8.605(2), p=.01$ & .986 & $.118(.046-.204)$ & 40.605 \\
\hline \multicolumn{5}{|l|}{ Restriction } \\
\hline Food Secure & $207.007(20), p<.01$ & .651 & $.237(.209-.267)$ & - \\
\hline Food Insecure & $92.144(20), p<.01$ & .706 & $.225(.180-.273)$ & - \\
\hline \multicolumn{5}{|l|}{ Pressure to eat } \\
\hline Food Secure & $1.848(2), p=.40$ & 1.000 & $.000(.000-.150)$ & - \\
\hline Food Insecure & $9.570(2), p<.01$ & .911 & $.231(.099-.386)$ & - \\
\hline
\end{tabular}

Note. Italicized analyses represent independent CFAs examining each subscale as a single factor. Perceived Parent Weight has 4 indicators, Concern about Child Weight has 3 indicators, Parental Responsibility has 3 indicators, Restriction has 8 indicators and Pressure to Eat has 4 indicators. AIC is a comparative fit index for two or more groups

The models for Enjoyment of Food, Desire to Drink, and Satiety Responsiveness all supported the configural, loading and intercept invariance. Thus, these subscales appear to be assessing the same underlying constructs and samples are endorsing items at similar threshold levels. Based on the AIC index, the intercept invariance model for Enjoyment of Food, the loading invariance model for Desire to Drink, and configural invariance model for Satiety Responsiveness are the optimal models (Table 7).

\section{Discussion}

Although there have been extensive studies that make group comparisons on child eating and feeding practices, few studies have examined measures to ensure group comparisons are equivalent across important group characteristics related to childhood obesity. Of note, there have been association studies relating minority groups' responses and scores on child eating and feeding practices measures to childhood obesity with limited research examining the appropriateness of these measures among minority groups. To further strengthen the research base for assessing child feeding practices and eating behaviors, we sought to evaluate the factor structure and measurement invariance of the CFQ and CEBQ across gender and ethnicity. A unique contribution of our study was the examination of household food security. It is important to ensure that child eating and feeding practices measures perform consistently across diverse environments.

Overall, results regarding the factor structure yielded mixed results for each measure and highlight some important issues to consider in assessing child eating and feeding practices. For the CFQ, the factor structures did not differ across any of the groups for the subscales Concern about Child Weight and Parental Responsibility. Our study is consistent with and adds to the existing psychometric literature. Cumulatively, Concern about Child Weight and Parent Responsibility, are invariant across Latinos (current study, [14]), African Americans [14], preschool-aged boys and girls (current study, [14, 27]) and diverse food secure environments [current study]. Most notably, the factor structures for Restriction, and Pressure to Eat from the CFQ varied across the ethnic and food security groups in the current study. It is important to note our findings add to the existing literature. There have been cross-cultural conceptual issues for the Restriction 
Table 7 Independent and multi-group CFAs for child eating in food secure and insecure households

\begin{tabular}{|c|c|c|c|c|}
\hline \multirow[b]{2}{*}{ Subscale } & \multicolumn{3}{|l|}{ Overall fit indices } & \multirow{2}{*}{$\begin{array}{l}\text { Comparative fit } \\
\text { AIC }\end{array}$} \\
\hline & $x^{2}(d f)$ & $\mathrm{CFI}$ & RMSEA $(90 \% \mathrm{Cl})$ & \\
\hline \multicolumn{5}{|c|}{ Child eating behaviour questionnaire } \\
\hline \multicolumn{5}{|l|}{ Food responsiveness } \\
\hline Food Secure & $7.902(5), p=.16$ & .985 & $.059(.000-.133)$ & - \\
\hline Food Insecure & $14.460(5), p=.01$ & .939 & $.163(.068-.265)$ & - \\
\hline \multicolumn{5}{|l|}{ Emotional overeating } \\
\hline Food Secure & $9.252(2), p=.01$ & .982 & $.148(.062-.250)$ & - \\
\hline Food Insecure & $3.071(2), p=.22$ & .994 & $.087(.000-.267)$ & - \\
\hline \multicolumn{5}{|l|}{ Enjoyment of food } \\
\hline Food Secure & $0.919(2), p=.63$ & 1.000 & $.000(.000-.122)$ & - \\
\hline Food Insecure & $1.103(2), p=.58$ & 1.000 & $.000(.000-.198)$ & - \\
\hline Configural Invariance & $2.026(4), p=.73$ & 1.000 & $.000(.000-.071)$ & 50.026 \\
\hline Loading Invariance & $2.618(7), p=.92$ & 1.000 & $.000(.000-.029)$ & 44.618 \\
\hline Intercept Invariance & $5.375(11), p=.91$ & 1.000 & $.000(.000-.026)$ & 39.375 \\
\hline \multicolumn{5}{|l|}{ Desire to drink } \\
\hline Food Secure & $0.000(0)$ & 1.000 & .000 & - \\
\hline Food Insecure & $0.000(0)$ & 1.000 & .000 & - \\
\hline Configural Invariance & $0.000(0)$ & 1.000 & .000 & 36.000 \\
\hline Loading Invariance & $0.038(2), p=.98$ & 1.000 & $.000(.000-.000)$ & 32.038 \\
\hline Intercept Invariance & $11.416(5), p=.04$ & .985 & $.074(.012-.131)$ & 37.416 \\
\hline \multicolumn{5}{|l|}{ Satiety responsiveness } \\
\hline Food Secure & $2.167(5), p=.83$ & 1.000 & $.000(.000-.064)$ & - \\
\hline Food Insecure & $4.392(5), p=.49$ & 1.000 & $.000(.000-.154)$ & - \\
\hline Configural Invariance & $6.579(10), p=.77$ & 1.000 & $.000(.000-.049)$ & 66.579 \\
\hline Loading Invariance & $20.049(14), p=.13$ & .976 & $.043(.000-.082)$ & 72.049 \\
\hline Intercept Invariance & $25.077(19), p=.16$ & .976 & $.037(.000-.072)$ & 67.077 \\
\hline \multicolumn{5}{|l|}{ Slowness in eating } \\
\hline Food Secure & $17.342(2), p<.01$ & .904 & $.215(.129-.313)$ & - \\
\hline Food Insecure & $2.063(2), p=.36$ & .999 & $.021(.000-.237)$ & - \\
\hline \multicolumn{5}{|l|}{ Emotional undereating } \\
\hline Food Secure & $2.852(2), p=.24$ & .996 & $.051(.000-.171)$ & - \\
\hline Food Insecure & $10.301(2), p<.01$ & .843 & $.242(.111-.397)$ & - \\
\hline \multicolumn{5}{|l|}{ Food fussiness } \\
\hline Food Secure & $27.170(9), p<.01$ & .969 & $.110(.064-.159)$ & - \\
\hline Food Insecure & $48.759(9), p<.01$ & .797 & $.249(.183-.320)$ & - \\
\hline
\end{tabular}

Note. Italicized analyses represent independent CFAs examining each subscale as a single latent factor. Food Responsiveness has 5 indicators, Emotional Overeating has 4 indicators, Enjoyment of Food has 4 indicators, Desire to Drink has 3 indicators, Satiety Responsiveness has 5 indicators, Slowness in Eating has 4 indicators, Emotional Undereating has 4 indicators, and Food Fussiness has 6 indicators. AIC is a comparative fit index for two or more groups

subscale among samples of Latinos (current study, [14]), African American [14, 40] and an Australian sample [27], and diverse food secure groups [current study]. It is important to note, that all of these studies, including the current study, assessed parents of preschool age children. For Pressure to Eat subscale, cross-cultural issues were found in the current study and Boles and colleagues [44], but Anderson and colleagues [14] found this scale to be invariant. In our study, the Perceived Parent Weight factor fit poorly across all the groups. Consistent with our findings, Anderson et al. [14] found issues with this factor and subsequently dropped it altogether. Given all of these findings, caution should be given to conclusions derived from studies that used these subscales across food secure samples $[17,18]$. Similarly, the lack of measurement invariance on Pressure to Eat and Restriction suggests findings from 
published studies demonstrating higher rates among Latinos compared to other ethnic and racial groups (i.e., $[11,16])$ should be interpreted with caution. Overall, results of the current study suggest that research should continue to validate the CFQ.

Results on the CEBQ revealed that three of the eight factors (Enjoyment of Food, Desire to Drink, and Satiety Responsiveness) performed well and did not vary across any of the groups. However, the intercepts did vary for Food Responsiveness where Latinos report lower thresholds for endorsing these items. In contrast, the intercepts varied for Emotional Overeating as well, but Latinos reported higher thresholds for endorsing these items when compared to non-Latino Whites. Importantly, the Food Fussiness factor showed poor fit across all of the groups. Other factors (i.e., Desire to Drink, Slowness in Eating, and Emotional Undereating) varied across the groups, suggesting the items in these subscales do not assess the same underlying construct across groups.

Cumulatively, the findings from the psychometric research on the CEBQ are mixed. Domoff et al. [22] conducted a validation study of the CEBQ among an ethnically diverse sample of low-income parents of preschool age children within the United States and replicated the original factor structure. A second study conducted on predominantly Hispanic and Black parents of preschool age children within the United States failed to replicate the original factor structure of the CEBQ and proposed three new factors [23]. Consistent with Domoff et al. [22], our study found that three of the food approach subscales (Food Responsiveness, Emotional Overeating, Enjoyment of Food) and one food avoidance subscale (Satiety Responsiveness) performed well across gender and ethnicity. But, consistent with Sparks \& Radnitz [23], Food Fussiness, Slowness in Eating, and Emotional Undereating had cross-cultural conceptual problems. It is important to note that all studies used parents of preschool age children, but differed in mode of administration. The current study along with Sparks \& Radnitz [23] administered self-report questionnaires while Domoff and colleagues [22] administered the questionnaire orally. At best, the collective research within the United States is inconclusive with regards to the construct validity of the CEBQ and highlights the need for further research.

A unique contribution of this study was an examination of measurement invariance across food secure and insecure households. For the CEBQ, Food responsiveness, which assesses external eating (e.g., responsiveness to sight, smell, and taste of palatable foods), and Food Fussiness, which assesses picky eating, failed to fit the data adequately. A closer examination of participants from food insecure households and their responses to food responsiveness and food fussiness items revealed higher rates of "untrue" endorsements. In addition, some parents wrote comments on these items stating those behaviors or situations did not occur. This might suggest that within food insecure environments, items from these subscales do not apply or fail to capture the living context of these families. In other words, the behaviors assessed in these items might be specific to households with consistent and stable food availability. Similarly, parental food restriction also may be only applicable in food secure environments given that within food insecure households the family economics and resources are placing food restrictions on the family. It is important to highlight that household food security is associated with income, however, food insecurity in children can still be quite high at incomes that are two or three times the poverty level [2]. Similarly, caregiver disability can influence the risk of food insecurity in children, but high rates can still be evident among households with employed caregivers [2]. Recent research has found that numerous factors aside from income and employment can influence household food insecurity including caregiver incarceration, immigration status, and caregiver's mental and physical health ([2] for a review). Since these analyses are unique to our study, replication is needed. Further research is need to explore how the presence of poor caregiver mental health or disability influences parent-report of child eating behaviors, if at all.

The results of this study should be interpreted in light of several limitations. First, the findings are limited to White and Latino samples fluent in English who are parents of preschool aged children. Second, the data are parent-report and may be influenced by context-specific eating behaviors and/or the desire to respond with socially expected answers. The very low food insecure and low food insecure were combined into one food insecure group due to sample size. Future research should consider separating this group as the very low food insecure group may differ significantly in feeding practices than the other groups. A larger sample size would have allowed for examining the entire factor structure of the scales within one CFA analysis. Relatedly, the number of analyses conducted increase the chance of family-wise error rate and the probability of making a type I error. This signifies that some of the $p$-values were significant simply by chance. Furthermore, this study was crosssectional in nature and cannot address longitudinal measurement invariance or distinguish between important differences among individuals that exist within specific racial groups, genders, or food security groups (i.e., genetics or individual experiences). Future research should consider conducting longitudinal measurement invariance with these variables, as this can address if changes on measurement over time reflect individual 
change or change in the properties of the measurement instrument.

\section{Conclusions}

In summary, continued psychometric research and scale refinement is needed on the CFQ and CEBQ. For the CFQ, Concern about Child Weight and Parental Responsibility subscales perform consistently across gender, ethnicity, and food secure environments. For the CEBQ, Enjoyment of Food, Desire to Drink, and Satiety Responsiveness subscales were invariant across all the contextual factors. Given that pediatric obesity is influenced by contextual factors such as gender, food security, and ethnicity, it is imperative that assessments perform consistently across these factors. The ability to assess risk factors for pediatric obesity, or to detect change across time in treatment studies or longitudinal studies, is compromised if the measures used are influenced by contextual factors.

\section{Abbreviations}

BMI: Body mass index; CEBQ: Children's Eating Behaviour Questionnaire: CFA: Confirmatory factor analysis; CFI: Comparative fit index; CFQ: Child Feeding Questionnaire; RMSEA: Root mean square error of approximation

\section{Acknowledgements}

The authors express gratitude for the families that participated in this research, and all the research assistants who helped and contributed to the efforts of Project ABC-EAT and the lab.

\section{Funding}

The project described was supported by Award Number R03HD058734 from the Eunice Kennedy Shriver National Institute of Child Health \& Human Development. The content is solely the responsibility of the authors and does not necessarily represent the official views of the Eunice Kennedy Shriver National Institute of Child Health \& Human Development or the National Institutes of Health.

\section{Availability of data and materials}

The dataset generated during the current study is not publicly available because MP and $\mathrm{JL}$ are analyzing the data, but are available from the corresponding author on reasonable request.

\section{Authors' contributions}

$\mathrm{MP}$ and $\mathrm{J}$ are the principal investigators on the grant and thus designed the study, operationalized study variables, and oversaw all aspects of the current study. MP, TO, AB conducted literature reviews, and drafted the manuscript. AT conducted analyses and drafted results. JL, AKVD and TU gave critical revision of the manuscript. MP finalized the manuscript. All authors read and approved the final manuscript.

\section{Ethics approval and consent to participate}

This study was approved by Texas A\&M University Institutional Review Board. Caregivers provided written consent to participate in the study.

\section{Competing interests}

The authors declare that they have no competing interests.

\section{Publisher's Note}

Springer Nature remains neutral with regard to jurisdictional claims in published maps and institutional affiliations.

\section{Author details}

'Department of Psychology, Arizona State University, 950 S McAllister Avenue, Tempe, AZ 85287-1104, USA. ²Department of Educational Psychology, Texas A\&M University, College Station, TX 77843-4225, USA.
${ }^{3}$ Nationwide Children's Hospital Department of Pediatric Psychology and Neuropsychology, The Ohio State University Department of Pediatrics, Cleveland, OH 44195, USA. ${ }^{4}$ Department of Psychology, Texas A\&M University, College Station, TX 77843-4235, USA.

Received: 31 January 2017 Accepted: 25 April 2018

Published online: 11 June 2018

\section{References}

1. Bhargava A, Jolliffe D, Howard LL. Socio-economic, behavioural and environmental factors predicted body weights and household food insecurity scores in the early childhood longitudinal study-kindergarten. Brit J Nutr. 2008;100:438-44

2. Gundersen C, Ziliak JP. Childhood food insecurity in the U.S.: trends, causes, and policy options. The future of children, fall 2014.

3. Ogden CL, Carroll MD, Kit BK, Flegal KM. Prevalence of childhood and adult obesity in the United States, 2011-2012. JAMA. 2014;311:806-14.

4. Wisniewski AB, Chernausek SD. Gender in childhood obesity: family, environment, hormones, and genes. Gender Med. 2009;6(Suppl 1):76-85.

5. Gross RS, Mendelsohn AL, Fierman AH, Racine AD, Messito MJ. Food insecurity and obesogenic maternal infant feeding styles and practices in low-income families. Pediatrics. 2012;130:254-61.

6. Martin KS, Ferris AM. Food insecurity and gender are risk factors for obesity. Jutr Educ Behav. 2007:39:31-6.

7. Metallinos-Katsaras E, Sherry B, Kalio J. Food insecurity is associated with overweight children in younger than 5 years of age. J Am Diet Assoc. 2009; 109:1790-4.

8. Ashcroft J, Semmier C, Carnell S, van Jaarsveld CHM, Wardle J. Continuity and stability of eating behavior traits in children. Euro J Clin Nutr. 2008;62:985-90.

9. Birch LL, Fisher JO, Grimm-Thomas K, Markey CN, Sawyer R, Johnson SL. Confirmatory factor analysis of the child feeding questionnaire: a measure of parental attitudes, beliefs and practices about child feeding and obesity proneness. Appetite. 2001;36:201-10.

10. Hughes SO, Anderson CB, Power TG, Micheli N, Jaramillo S, Nicklas TA. Measuring feeding in low-income African-American and Hispanic parents. Appetite. 2006;46:215-23.

11. Taveras EM, Gillman MW, Kleinman K, Rich-Edwards JW, Rifas-Shiman SL. Racial/ethnic differences in early-life risk factors for childhood obesity. Pediatrics. 2010;125:686-95.

12. Wardle J, Guthrie C, Sanderson S, Birch L, Plomin R. Food and activity preferences in children of lean and obese parents. Int J Obesity. 2001;25:971-7.

13. Wardle J, Guthrie CA, Sanderson S, Rapoport L. Development of the Children's eating behaviour questionnaire. J Child Psychol Psyc. 2001;42:963-70.

14. Anderson CB, Hughes SO, Fisher JO, Nicklas TA. Cross-cultural equivalence of feeding beliefs and practices: the psychometric properties of the child feeding questionnaire among blacks and Hispanics. Prev Med. 2005;41:521-31.

15. Blissett J, Meyer C, Haycraft E. Maternal and paternal controlling feeding practices with male and female children. Appetite. 2006:47:212-9.

16. Cardel M, Willig AL, Dulin-Keita K, Casazza K, Beasley M, Fernandez JR. Parental feeding practices and socioeconomic status are associated with child adiposity in a multi-ethnic sample of children. Appetite. 2012;58:347-53.

17. Matheson DM, Robinson TN, Varady A, Killen JD. Do Mexican-American mothers' food-related parenting practices influence their children's weight and dietary intake? J Am Diet Assoc. 2006;106:1861-5.

18. Gross RS, Velazco NK, Briggs RD, Racine AD. Maternal depressive symptoms and child obesity in low-income urban families. Acad Pediatrics. 2013;13:356-63.

19. Wehrly SE, Bonilla C, Perez M, Liew J. Controlling parental feeding practices and child body composition in ethnically and economically diverse preschool children. Appetite. 2014;73:163-71.

20. Mallan KM, Liu W, Mehta RJ, Daniels LA, Magarey A, Battistutta D. Maternal reports of young children's eating styles. Validation of the Children's eating behaviour questionnaire in three ethnically diverse Australian samples. Appetite. 2013;64:48-55.

21. Svensson V, Lundborg L, Cao Y, Nowicka P, Marcus C, Sobko T. Obesity related eating behaviour patterns in Swedish preschool children and association with age, gender, relative weight and parental weight-factorial validation of the Children's eating behaviour questionnaire. Int J Behav Nutr Phy. 2011;8:134 
22. Domoff SE, Miller AL, Kaciroti N, Lumeng JC. Validation of the Children's eating behaviour questionnaire in a low-income preschool-aged sample in the United States. Appetite. 2015;95:415-20.

23. Sparks MA, Radnitz CL. Confirmatory factor analysis of the Children's eating behaviour questionnaire in a low-income sample. Eat Behav. 2012;13:267-70.

24. Cross MB, Hallett AM, Ledoux TA, O'Connor DP, Hughes SO. Effects of children's self-regulation of eating on parental feeding practices and child weight. Appetite. 2014;81:76-83.

25. Webber L, Hill C, Saxton J, van Jaarsveld CHM, Wardle J. Eating behaviour and weight in children. Int J Obesity. 2009;33:21-8.

26. Spence JC, Carson V, Casey L, Boule N. Examining behavioural susceptibility to obesity among Canadian pre-school children: the role of eating behaviours. Pediatric Obesity. 2011;6:e501-7.

27. Corsini N, Danthiir V, Kettler L, Wilson C. Factor structure and psychometric properties of the child feeding questionnaire in Australian preschool children. Appetite. 2008;51:474-81.

28. Kuczmarski RJ, Ogden CL, Grummer-Strawn LM, Flegal KM, Guo SS, Wei R, et al. CDC growth charts: United States. Adv Data. 2000;314:1-27.

29. Bickel G, Nord M, Price C, Hamilton W, Cook J. Guide to measuring household food security. Department of Agriculture Food and Nutrition Service. 2000.

30. Nord M, Andrews M, Winicki J. Frequency and duration of food insecurity and hunger in US households. J Nutr Educ Behav. 2002;34:194-200.

31. Rose D, Bodor JN. Household food insecurity and overweight status in young school children: results from the early childhood longitudinal study. Pediatrics. 2006:117:464-70.

32. Wolf EJ, Harrington KM, Clark SL, Miller MA. Sample size requirements for structural equation models: an evaluation of power, bias, and solution propriety. Educ Psychol Meas. 2013;76:913-34.

33. Meade AW, Bauer DJ. Power and precision in confirmatory factor analytic tests of measurement invariance. Struct Equ Modeling. 2007;14:611-35.

34. MacCallum RC, Widaman KF, Zhang S, Hong S. Sample size in factor analysis. Psychol Methods. 1999:4:84-99.

35. Preacher KJ, Coffman DL. Computing power and minimum sample size for RMSEA [computer software] 2006. Available from: http://quantpsy.org.

36. Muthén B, Muthén L. Mplus [computer software]. Los Angeles: Muthén \& Muthén; 1998

37. Mulaik SA, Millsap RE. Doing the four-step right. Struct Equ Model. 2000;7:36-73.

38. Enders CK, Bandalos DL. The relative performance of full information máximum likelihood estimation for missing data in structural equation models. Struct Equ Model. 2001;8:430-57.

39. Bollen KA. Structural equations with latent variables. New York City: Wiley; 1989.

40. Steiger JH. Structural model evaluation and modification: an interval estimation approach. Multivar Behav Res. 1990;25:173-80.

41. Bentler PM. Comparative fit indices in structural models. Psychol Bull. 1990; 107:238-46.

42. Browne MW, Cudeck R. Alternative ways of assessing model fit. In: Bollen KA, Long JS, editors. Testing structural equation models. Newbury Park: Sage; 1993. p. 136-62.

43. Brown T. Confirmatory factor analysis for applied research. New York: Guilford Press; 2006.

44. Boles RE, Nelson TD, Chamberlin LA, Valenzuela JM, Sherman SN, Johnson SL, Powers SW. Confirmatory factor analysis of the child feeding questionnaire among low-income African American families of preschool children. Appetite. 2010;54:402-5.

\section{Ready to submit your research? Choose BMC and benefit from:}

- fast, convenient online submission

- thorough peer review by experienced researchers in your field

- rapid publication on acceptance

- support for research data, including large and complex data types

- gold Open Access which fosters wider collaboration and increased citations

- maximum visibility for your research: over $100 \mathrm{M}$ website views per year

At BMC, research is always in progress.

Learn more biomedcentral.com/submissions 